\title{
REVIEW
}

\section{Nature and consequences of biological connectivity in mangrove systems}

\author{
Marcus Sheaves* \\ School of Marine Biology and Aquaculture, James Cook University, Townsville, 4815 Queensland, Australia
}

\begin{abstract}
Mangroves are important nursery and feeding areas for fish. Their rich invertebrate faunas render them productive feeding areas, while their shallow waters and structural complexity provide sanctuary habitats at a variety of scales. However, in most parts of the world mangroves are available to fish for only part of the time because they are alternately inundated and exposed by the high-tide/low-tide cycle. As a result, few fish can use mangroves exclusively but must migrate in and out of the mangroves with the tide, occupying alternative habitats when mangroves are unavailable. These movements connect the mangroves and the alternative habitats to form an 'interconnected habitat mosaic'. Living in a habitat mosaic puts limits on the patterns of life possible in mangrove systems, complicates trophic structures, and creates the need for tactics and strategies to meet the challenges imposed by movement among components of the mosaic. Moreover, this biological connectivity means that understandings of trophic relationships, life-history strategies, predation and mortality, and patterns of distribution and abundance must be set in a spatially and temporally variable context. Despite the obvious consequences and importance of biological connectivity in mangrove ecosystems, it has often not been given appropriate consideration in the development of theories and paradigms.
\end{abstract}

KEY WORDS: Biological connectivity $\cdot$ Mangrove $\cdot$ Estuary $\cdot$ Fish $\cdot$ Movement

\section{INTRODUCTION}

Mangroves are a feature of low-energy intertidal habitats in tropical and warmer temperate areas throughout the world (Duke 1992, Woodroffe 1992, Duke et al. 1998). This includes protected coastlines, barrier islands, coral atolls and coral keys, as well as estuaries, and river deltas. Mangrove species and forest structure vary with location (latitude, geographic setting and tidal regime) and climate, but their role in contributing structural complexity and productivity to intertidal areas does not.

Mangroves are recognised for their value as nurseries for juvenile fish (Beck et al. 2001). The rich invertebrate fauna of mangrove forests (Sheridan 1997) renders them productive feeding areas (Bell et al. 1984, Tahir 1988, Quinn 1993, Sheaves \& Molony 2000), while their shallow waters and structural complexity
(Thayer et al. 1987) can provide sanctuary habitats at a variety of scales (Bell et al. 1984, Amarasinghe 1997). The nursery, feeding and protective roles are not mutually exclusive, but interact in complex ways. For instance, a juvenile fish may simultaneously gain nursery advantages from a rich supply of food and the protection afforded by prop roots (Laegdsgaard \& Johnson 2001). Moreover, juvenile fish may themselves be piscivores targeting smaller fish sheltering and feeding in the forest (Sheaves 2001).

The importance of mangroves to fish goes beyond a nursery role. As with juveniles, adult fish can gain benefit by accessing rich feeding areas and/or protective habitats (Robertson \& Duke 1990). Additionally, mangroves can be important sites for reproduction (Chaves $\&$ Bouchereau 2000). The relative importance of the various advantages changes from species to species, from time to time, from place to place and over 
ontogeny, adding more diversity to the way fishes use mangroves. Additionally, at any one time and place, different species may have different reasons for utilising these habitats (Rountree \& Able 1997). Such intricacy makes understanding the advantages and disadvantages of using mangrove habitats a convoluted, multifaceted, multispecies problem, and complicates explanations of value that relate to such things as feeding and refuge from predation.

In locations such as Curaçao (Nagelkerken et al. 2001) and Florida (Ley et al. 1999), a small tidal range means that mangrove habitats are continuously available to fish. Additionally, in some areas ponds remain in the mangroves at high tide (Huehner et al. 1985). However, these are usually very limited in extent compared to the area of mangrove forest, are often ephemeral and prone to extreme variations in physical conditions (Heath et al. 1993), and can support only a few specialised species. Beyond these situations, in most parts of the world mangroves are alternately inundated and exposed by the high-tide/low-tide cycle, and few fish (except some highly adapted species; Davis et al. 1995, Kok et al. 1998) can use mangroves exclusively, but must migrate in and out with the tide (Gundermann et al. 1983).

In locations where mangroves are not continuously available, most fish that use mangroves as a protective habitat must either use an alternative protective habitat when the tide is out of the mangroves or risk higher rates of mortality while mangroves are unavailable. Similarly, fish that use mangroves for feeding either need an alternative feeding habitat while the tide is out or must refrain from feeding while mangrove areas are unavailable. Even in areas where mangroves remain flooded for much of the year, many mobile animals undergo movements among habitats for feeding, reproduction and stage-specific habitat use (Nagelkerken et al. 2001). Therefore, any advantage accruing from the utilisation of mangroves has to be set in the context of connectivity with other habitats. As a result, where they are intermittently available, mangroves must be considered as only part of an 'interconnected habitat mosaic' (IHM).

The function of mangroves in providing food and protection for fishes is well accepted, and the temporal availability of these intertidal areas makes biological connectivity between mangroves and adjacent habitats a necessary fact. Consequently, understanding the ecology, distribution and energetics of species using mangroves relies on a detailed knowledge of the relationships between species and the range of habitats they exploit. Additionally, the process of interhabitat migration not only links the habitat units, it poses a range of challenges that makes these transitions crucially important events and the potential foci for pro- cesses regulating the use of the IHM. Understanding these transitions is one of the keys to understanding the functioning of the whole system.

Here I investigate biological connectivity within the mangrove IHM: the nature of the mosaic, the consequences of species utilising multiple habitats and the implications of the need to migrate between components of the mangrove IHM. I will focus principally on fish, because their mobility, and the need for most species to remain continually submerged, makes interhabitat migration a necessity (the corollary of this is that fish play a particularly important role in linking the units of the mangrove IHM). Despite the principal focus on fish, examples and understandings have also come from many other taxa, because this discussion applies equally to many other mobile animals. Additionally, because many issues pertinent to mangrove connectivity have received little study, much of the current understanding has to be inferred from knowledge gained in other environments.

\section{THE NATURE OF THE MANGROVE IHM}

In parts of the world where microtidal conditions mean that mangroves fringing waterways are inundated throughout the tide (Ley et al. 1999, Nagelkerken et al. 2001), the use of alternative habitats at low tide may be unnecessary. Here biological connectivity may be restricted to a seasonal, ontogenetic or food-related progression among a series of habitats. However, the use of alternative habitats is an obvious necessity in areas where the tidal range and tidal pattern exclude fish from mangroves for part of the time. Even where tidal ranges are reasonably small, fish are often excluded from the mangroves for extended periods of time (dotted line in Fig. 1), and there is an even longer period when little mangrove habitat is available (e.g. dashed line in Fig. 1). If there is also effectively a single tidal cycle per day, fish may have to occupy alternative habitats for extended periods. Where the tidal range is greater and tides are more frequent mangroves are still unavailable for much of the time, and changes in availability over the lunar cycle become more extreme (Fig. 2). Thus, although the extent of utilisation may differ due to access, wherever fish are periodically excluded from mangroves, they must possess a specific set of strategies that allow movement to and occupation of alternative habitats, while optimising the trade-off between predation risk and food availability (Sogard 1992, Allouche 2002). These strategies are likely to be species and size specific, and set in the context of spatial and temporal changes in predation risk and food availability. Thus 
there are a host of factors that influence and modify biological connectivity and affect the stability of connections over space and time.

\section{Are mangroves 'just another shallow-water habitat'?}

Mangrove utilisation may be obligate for some species, but is this the case for the majority of fish that use mangroves? Although the evidence is equivocal
(Sheaves 2001, Speirs et al. 2002), it is widely considered that shallow waters per se are important habitats for fish, particularly juveniles, because they provide refuge from predation (e.g. McIvor \& Odum 1988, Paterson \& Whitfield 2000). Given the temporary nature of mangrove utilisation, and the necessity for fish to use other parts of the IHM as well as mangroves, many species may simply move to stay in shallow water throughout the tide. In this case mangroves may simply be just another complex habitat or even just
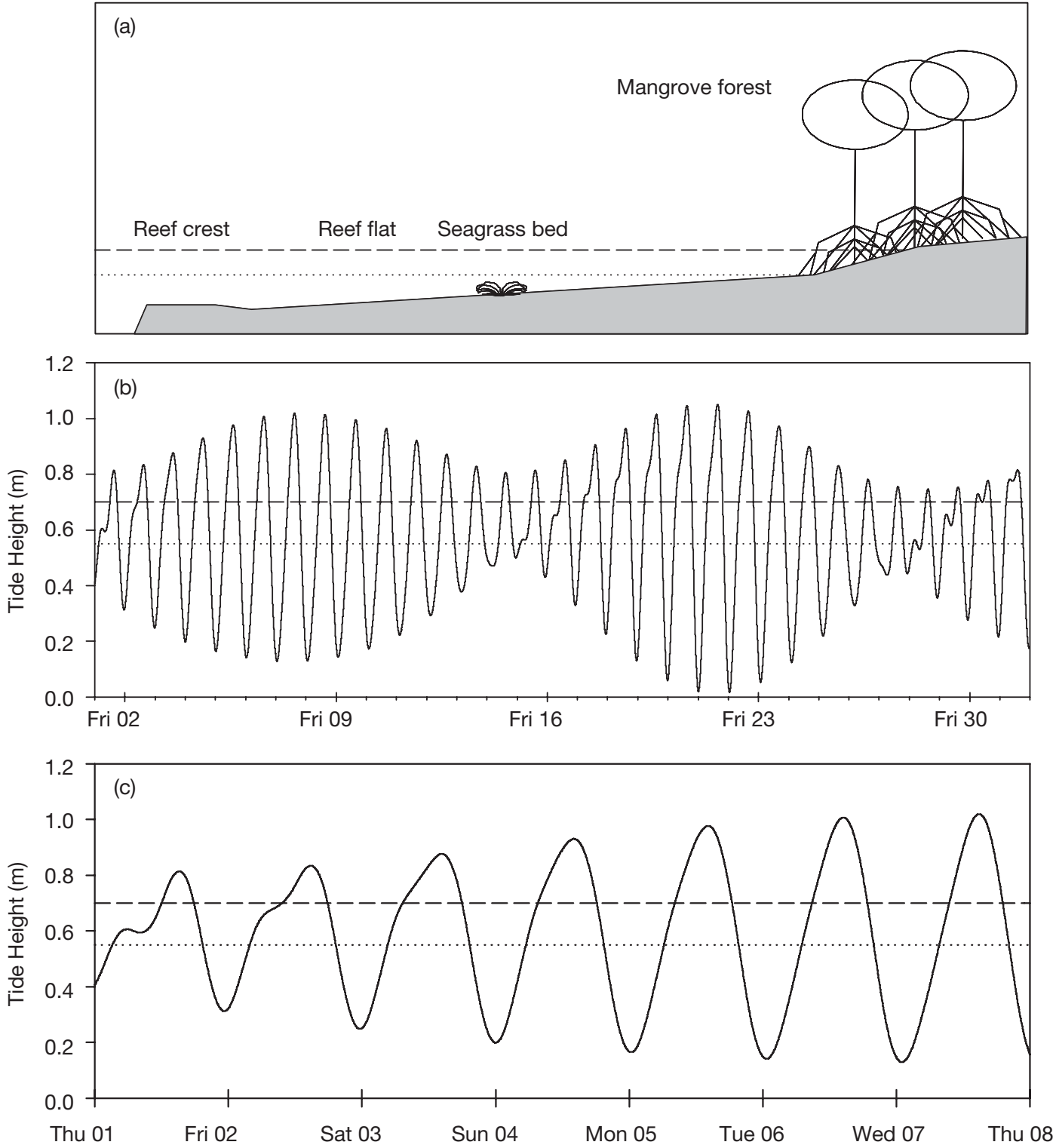

Fig. 1. Tide levels for Kimbe Bay, New Britain, Papua New Guinea, an area with a small tidal range and essentially a single tide per day. (a) Schematic of a typical intertidal profile at Kimbe Bay, (b) tide track for January 2004, and (c) tide track for the first week of January 2004. Tick marks represent midnight of each day. Dotted line represents the approximate tide height at which water begins to enter the mangroves. Dashed line is the approximate height when water has entered all forests except those on erosional banks. At this level extensive areas have begun to be inundated. Tidal data supplied by the Australian National Tidal Centre 

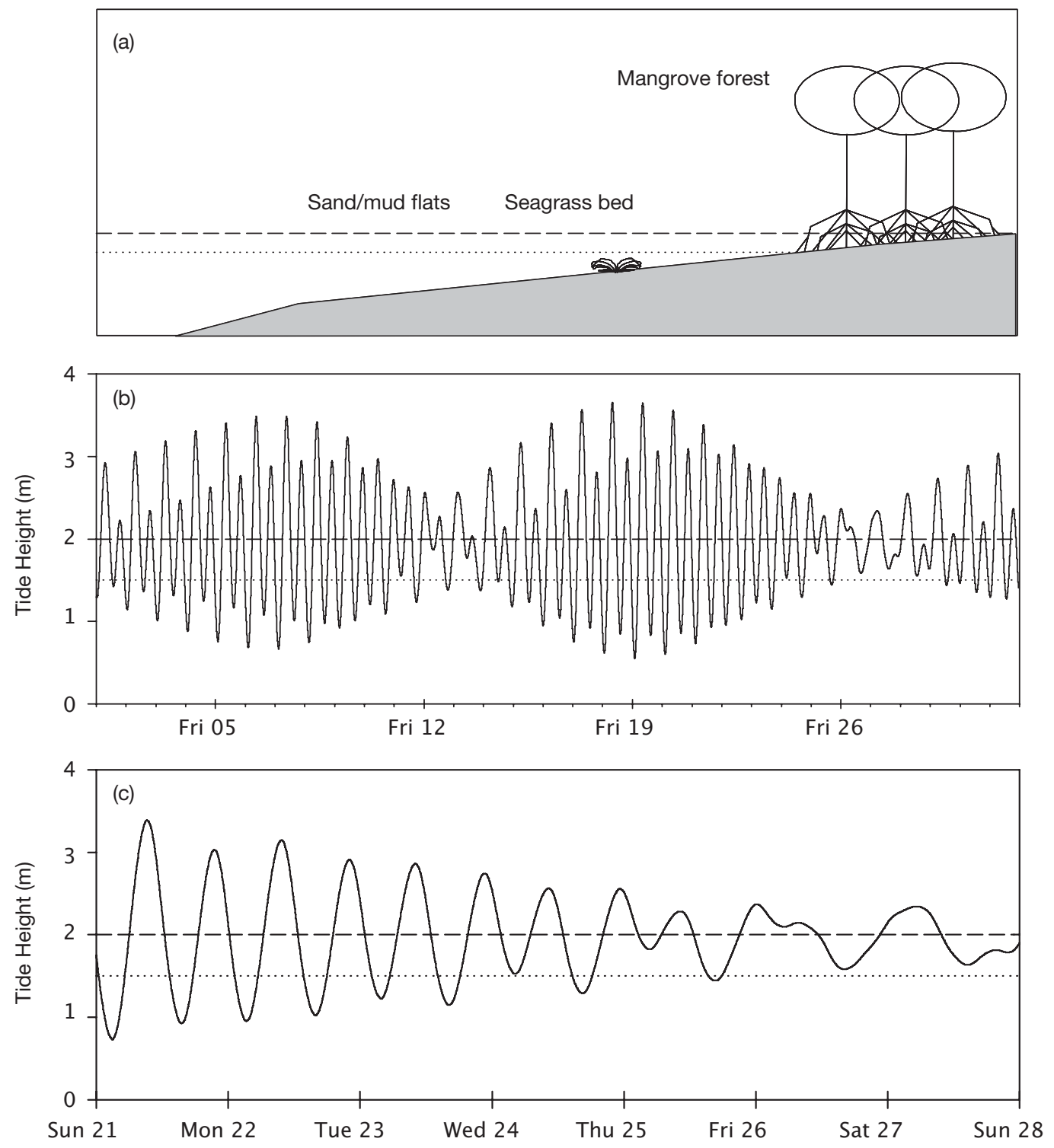

Fig. 2. Tide levels for Lucinda, northeastern Australia, an area with a moderate tidal range and usually 2 tides per day. (a) Schematic of a typical intertidal profile at Lucinda, (b) tide track for March 2004, (c) tide track for the first week of March 2004. Tick marks represent midnight of each day. Dotted line represents the approximate tide height at which water begins to enter the mangroves. Dashed line is the approximate height when water has entered all forests except those on erosional banks. At this level extensive areas have begun to be inundated. Tidal data supplied by the Australian National Tidal Centre

another shallow-water habitat. If so, the role of mangroves in the habitat mosaic could be performed just as well by salt marsh vegetation, by fallen timber or rocks, or even by bare areas of shallow water alone. So is it the mangroves themselves, or simply shallow water, that is important? This question is difficult to answer, but evidence that mangroves are more than just 'another shallow-water habitat' comes from Curaçao, an area where a small tidal range means that mangrove habitats are continuously available to fish.
There, mudbanks in bays with mangroves have much higher abundances of juvenile fish and more species than those in bays without mangroves (Nagelkerken et al. 2001, Nagelkerken \& van de Velde 2002), suggesting a role for mangroves beyond that performed by similar shallow-water habitats lacking mangroves. A similar situation seems to exist in areas where mangroves are available through only part of the tide (Ikejima et al. 2003), although the evidence is more equivocal. 
In terms of food supply, mangroves also appear to be more than just another shallow-water habitat. Habitatspecific studies have shown mangroves provide higher densities of small benthic prey than nearby habitats (Sheridan 1997), although this is not always the case (Nagelkerken \& van der Velde 2004). In addition to an abundant benthic fauna, the structural complexity of mangroves provides a high surface area for the attachment of microbes, epifauna and sessile animals (Hannan 1998), which are fed on by fish that move into the mangroves at high tide (Gundermann et al. 1983, Duncan \& Szelistowski 1998).

\section{What does the habitat mosaic look like?}

For species requiring alternative refuges from predation when the structural complexity of mangroves is unavailable, protection could be afforded by woody debris (snags) (Sheaves 1996), seagrass beds (YanezArancibia et al. 1994), and coral (Hixon 1993), oyster (Lehnert \& Allen 2002) or rocky (Lowry 2003) reefs. The usefulness of a habitat type to an individual relates, at least in part, to the scale of the habitat. For example, an alternative protective habitat for a fish using mangroves as a predation refuge would probably need to provide refuge spaces of the same size as those afforded by the mangroves (Hixon 1993). In many areas changes in water depth over the tidal cycle necessitates the use of a series of alternative refuges; for example, mangroves, which typically receive the shortest duration of flooding of intertidal habitats (Sheridan 1997), may provide refuges only during the highest parts of the tide, seagrass during intermediate tidal levels, and fringing reefs when both mangroves and seagrass beds are exposed (e.g. Fig. 1).

Obviously, fish need feeding areas as well as refuge areas. In fact there are 4 main patterns for the use of the IHM. (1) For species that feed in mangroves, alternative habitats could act as non-feeding protective habitats. In this case, only one or some of the connected habitats would be used as a refuge. (2) Fish that feed in mangroves may use an alternative habitat(s) as a feeding area when mangroves are unavailable. In this case one, both or neither habitats might also provide refuge. Fish using multiple feeding habitats would require a catholic diet and perhaps a range of feeding strategies. (3) Fish may use mangroves as refuges when water depths in their preferred feeding habitat become great enough to allow predators to enter. (4) Alternatively, some species may be insensitive to structural complexity and simply enter components of the habitat mosaic incidentally while carrying out pursuits such as feeding.
There are probably few instances where the fish use a series of connected complex habitats exclusively. Many of the same species are found in open habitats as are found in structurally complex mangrove and seagrass habitats (Nagelkerken et al. 2001, Ikejima et al. 2003), but their densities are often much greater in complex habitats (Sheaves 1996). The non-exclusive use of the IHM is not surprising because the exclusive or near-exclusive use of complex habitats is only likely where the benefits of using those habitats far outweigh the benefits of using alternative habitats.

\section{Factors modifying biological connectivity}

Biological connectivity needs to be studied in the context of potential modifying factors and mechanisms. These include such things as tidal regime, the particular phase of the tidal cycle, the availability of alternative habitats, the location-specific productivity at different sites, the mix of species present in a system, the life-history strategies of those species, the spectrum of predators present, and the types of food available.

The local tidal regime probably has one of the greatest influences on the pattern of biological connectivity. For example, where the tidal range is extreme, water depths may be great enough to allow large predators to readily access mangroves at high tide, thereby reducing refuge value (Blaber 1986). Additionally, variations in the number of tides per day and the relative height of high and low tides influence the need and ability of fish to access different habitats. Moreover, for many species the greater physical distance between habitats and the effect of high current velocities (Rosenfeld \& Boss 2001) probably make movements between habitats components more difficult and energetically expensive in macro- than micro-tidal areas.

The nature of the connectivity imposed by the tidal regime is modified by changes in the extent and duration of tidal movements over the course of the lunar tidal cycle. In areas where access to intertidal vegetation is extensive during spring tides, there may be little or no access to those same habitats on neap tides (Kneib 1997). Thus the behaviour of fish must be plastic enough to allow them to alter their patterns of movement and the way they use habitats to optimise the trade-off between food acquisition and predator avoidance over the full range of tidal conditions.

Mangrove systems (i.e. areas that include mangrove IHMs) provide diverse mixes of habitats (Hannan 1998), and biological connectivity is modified by the exact mix of alternative habitats available. Where behaviour is sufficiently plastic, and the necessary 
attributes (food, protection, etc.) are available in an alternative habitat, using that alternative habitat presents few problems (besides those related to interhabitat movement-see below). If, on the other hand, no appropriate alternative habitat is available locally, fish may need to increase the distance of their tidal migration (potentially with an attendant increase in exposure to predation) and accept the resulting energetic cost (Bernatchez \& Dodson 1987, Alexander 2002). In extreme cases, there may be no suitable habitat available at all. If so, they either cannot use that mangrove area or must utilise a suboptimal alternative habitat when the mangroves are not available and accept the accompanying disadvantages.

Location-specific differences in productivity at different sites can influence the pattern of biological connectivity, because highly productive habitats are likely to be more attractive feeding sites (Laffaille et al. 2000). Higher productivity can also lead to greater refuge value. For example, large, dense beds of seagrass may provide ample food and/or extensive areas of refuge (Sogard 1992), obviating the need to migrate to mangroves. In contrast, in other areas small, sparse seagrass beds may not provide sufficient food or refuge, necessitating movement into mangroves at high tide. Similarly, differences in turbidity may change the extent and depth range of seagrass beds from place-to-place (Moore et al. 2003), altering their value in the IHM.

All these factors interact with the species mix at each site, specific patterns of predation risk, trade-offs between predation risk and food acquisition, and species-specific life-histories. The need for refuge is further influenced by the spectrum of predators with which fish must co-exist (e.g. whether there are few or many piscivorous birds or specialist shallow-water fish predators), while importance as feeding areas is influenced by the types and quantities of food available.

\section{CONSEQUENCES AND IMPLICATIONS OF BIOLOGICAL CONNECTIVITY}

Biological connectivity is a real and necessary consequence of using mangroves. It imposes complexity and variety on all aspects of life for fish using the mangrove IHM. Connectivity is important because it circumscribes the patterns of life possible for many fish. As is the case in coupled lake habitats (Schindler \& Scheuerell 2002), it complicates such things as community structure, physiology, life-history, trophic structure and predator-prey interactions, and to a large extent it determines the range of tactics and strategies available to mobile animals. At the same time it provides fishes with unique opportunities.

\section{Consequences of using multiple habitats}

Trophic relationships

The necessity of using multiple habitats has far reaching consequences for trophic organisation; it simultaneously links food webs in different habitats and complicates patterns of trophic organisation.

The various components of the IHM represent a diverse group of marine habitats. They differ greatly in structural complexity and the natures of their primary producers: from mangroves and seagrass to algae and phytoplankton. Moreover, their locations at different tidal levels means they possess very different environmental conditions. Consequently, each contains a distinct resident fauna (Laegdsgaard \& Johnson 1995) and possesses a definable, and largely unique, trophic organisation. As part of a habitat mosaic, these individual trophic webs interact in intricate ways. For example, mangrove forests are notable for their strong recycling of nutrients (Alongi et al. 1993). Herbivorous animals, such as sesarmid crabs, feed on mangrove leaf litter and other debris, greatly reducing the quantity of nutrients flushed away from the forest by water movements (Robertson 1991). Mobile animals link the mangrove forest to the other trophic units of the IHM and transfer energy away from mangroves to other components of the habitat mosaic (Sheaves \& Molony 2000). This movement of nutrients through migration, linking food webs in different habitats, has 2 important consequences. Firstly, it disrupts mangrove recycling (Sheaves \& Molony 2000). Secondly, it provides nutrient subsidies to subtidal habitats. Nutrient subsidies are crucial in foodweb functioning because they create the possibility for enhanced abundances of both detritivores and carnivores in the other components of the habitat mosaic (Polis et al. 1997). This export of energy can also work in reverse for animals that feed in the subtidal then move into mangroves, where they are preyed upon by resident fauna. The relative importance of the movement of energy in the 2 directions is linked to the overall balance between the use of mangroves as feeding areas and their use simply as refuges from predation.

This movement among what are, on the face of it, discrete food webs, complicates trophic organisation (Polis \& Strong 1996). Food webs, already complicated by processes such as the recycling of nutrients (Robertson 1991) and ontogenetic diet shifts (Wilson \& Sheaves 2001), are further complicated by fishes migrating between webs, because individuals can participate in different food webs at different points in time and space. Consequently, the trophic role of a species in a single food web cannot be clearly defined, 
both because it is likely to obtain nutrients in more than one web and because it can be preyed upon in webs different to those in which it feeds.

Implications for particular trophic groups

Many authors have discussed the role of mangroves in providing food and refuges from predation for juvenile fish, and the consequences of this for biological connectivity have been discussed above. However, the implications for particular trophic groups that use mangroves as part of a mosaic of connected habitats has received much less attention.

The relationship between predators and the mangrove IHM is complicated and ambiguous. It is ambiguous because predators come in all sizes, leading to a paradox: for a small predator any protection afforded by a complex structure should in turn reduce that predator's own feeding efficiency (Sheaves 2001). Obviously, any reduction in predation depends on the relative size of predator and prey relative to the scale of the habitat. For example, the scale of structural complexity provided by the prop roots of any particular mangrove stand is of a characteristic scale (Roennbaeck et al. 1999, Bell et al. 2003), providing refuge to a particular size range of prey from a particular size range of predators. Clearly, a mangrove stand does not exclude the full size range of potential predators for a particular prey, but it does limit the size range of predators that can be effective. On the other hand, dependent on capture strategy, some predators may be advantaged by the availability of ambush sites or by habitat structure disrupting the integrity of protective schools (Flynn \& Ritz 1999). Moreover, although the feeding of some predatory fish is inhibited by the structural complexity of mangroves, prey capture in other species is not greatly disrupted (Primavera 1997).

\section{Temporal refuges}

Because of their position high in the intertidal, mangroves typically experience a shorter duration of inundation than most other intertidal habitats (Sheridan 1997). Consequently, the abundant mangrove benthos, epiflora and epifauna (Hannan 1998) can only be accessed by fish for a short period each tidal cycle, providing the organisms with a substantial temporal refuge from predation by marine predators. When fish are excluded from the intertidal, benthos able to remain active while the intertidal is exposed (Warren 1990), or utilise surface films (Kruse \& Buhs 2000) or shallow water for feeding, can conduct their lives with- out exposing themselves to predation by fish. This effect could explain the high abundances of benthos in intertidal areas (Sheridan 1997), which, in turn, makes them attractive feeding areas for fish when they are available.

Implications for controlling mechanisms

The use of the IHM and the consequent interhabitat migrations greatly complicate any understanding of mechanisms controlling ecological patterns, processes and parameters. This complication arises because the nature of ecological patterns in any one habitat is likely to be a consequence of, or influenced by, events in a different part of the mangrove IHM. In fact, the temporally variable nature of use of each component of the IHM means that events in one component of the habitat mosaic can exert a controlling influence that is manifested throughout the mosaic. This allows the possibility of strong ecological bottlenecks, and for outcomes in one habitat to be largely unrelated to events occurring there. For instance, juveniles of the tropical lutjanid Lutjanus argentimaculatus use estuaries as nursery grounds and feed predominantly on mangrove-associated sesarmid crabs (Sheaves \& Molony 2000). They enter the mangroves to feed at high tide and retreat to subtidal areas, particularly submerged snags, at low tide. Accordingly, the absence of snags in a particular estuary is likely to result in low abundances of $L$. argentimaculatus, regardless of the extent of mangrove areas available to them.

Controlling mechanisms are further complicated because the location where control occurs and even the controlling factors themselves may change over time. Furthermore, the necessity of movement and multiple habitat use means that the influence of a controlling factor that only operates in one habitat at one time can be propagated throughout the IHM. Thus it is crucial to consider events in all its components over all temporal scales if a clear understanding of the mechanisms and factors controlling ecological patterns in the IHM is to be achieved.

\section{Implications of migrating between habitat units}

The need to use multiple components of the mangrove IHM has substantial consequences for the ecology, distribution and energetics of the species involved. At least as important are the implications of interhabitat migrations. The necessity of migration makes interhabitat transitions potential ecological bottlenecks, primarily because when migrating fish are exposed to an increased risk of predation. Inter- 
habitat migration also has energetic costs and entering temporally available habitats makes stranding an ever present danger (Adams et al. 1999).

\section{Tactics for interhabitat migration}

Living with the necessity of moving between a series of habitats on a daily basis (Gundermann et al. 1983) requires a suite of tactics to deal with the challenges imposed by interhabitat migration. For instance, daily migration to and from the mangroves involves passing between contrasting habitats and passing across clearly defined structural boundaries between habitats (Kneib 1997). Where the refuge value of a structurally complex habitat is an important motivation for using mangroves, migration between areas of structural complexity should logically involve increased risk because fish must pass through zones where protection from predation is diminished (Heck \& Thoman 1981, Savino \& Stein 1982, Sogard \& Able 1994). In addition, the mere act of movement between habitats is likely to increase mortality because detection by predators and the reactive distance of predators is substantially increased by prey movement (Crowl 1989).

Fish probably also require specific tactics for entering mangroves. On rising tides fish could follow the movement of the tide by remaining in the shallowest depth they can inhabit. Such behaviour would need to be modified in the face of predation. For example, the presence of piscivorous wading birds (Miranda \& Collazo 1997) may increase the risk of occupying the shallowest water possible, although the effect is not simple (Crowder et al. 1997), and the presence of active predatory fish (Blaber 1986) would probably make a slow movement across open habitats undesirable. Where the major incentive for entering mangroves is to access food, following the shallow-water edge as the tide rises would provide the opportunity to be the first to access rich supplies of food (Sheridan 1997, Gibson 2003) as they become available. Such a tactic would seem to be particularly important to fish specialising in feeding on prey such as crabs (Sheaves \& Molony 2000) and amphipods that take refuge soon after the tide reaches them (Warren 1990, Odendaal et al. 1999), and benthic animals whose feeding activity is attuned to utilising the first influx of tidal water.

Exiting mangrove areas presents even more difficulties. Although remaining in mangroves as long as possible would maximise protection from predation and time for feeding, there is a clear trade-off against the danger of being trapped in shallow water by the falling tide (Gibson 2003). Where the major motivation for entering the mangroves is to feed, rather than to gain a refuge from predation, leaving soon after the tide begins to fall would seem a judicious tactic. Any advantage of feeding close to the advancing waters edge, which was there on the flooding tide, no longer exists, and the ebbing tide could provide a cue to initiating departure while ample water remained in the mangroves. Indeed, fish that inhabit littoral areas often exhibit behaviours, such as swimming with the current or drifting passively (Adams et al. 1999), that are likely to reduce stranding, as long as the behaviours are initiated before the tide falls too far. Where refuge from predation is the major motivation for entering mangroves, remaining in the mangroves as long as possible would maximise the advantage. In this case specialised tactics for minimising the chance of stranding, while delaying exit from the mangroves as long as possible, would clearly be advantageous.

\section{Predation risk}

Making transitions between habitats is likely to increase the risk of predation (Sogard \& Able 1994, Hiddink et al. 2002), so that whether to move or not represents a trade-off between the risk of moving and the advantages gained (Fig. 3). This trade-off is different depending on whether the primary motivation for movement is to gain refuge from predation or to access food. There is probably a different balance between these 2 motivations for each species, but considering the 2 extreme cases is instructive.

If the motivation is primarily to access food resources, as is the case for many fish (Gibson 1992, 1999), there are 3 possibilities. Firstly, if a species relies on food resources only available in mangroves, migration must continue regardless of the risk of predation during migration (Fig. 3a). In contrast, where mangrove food resources are desirable but access to them is not crucial because there are alternative feeding areas, there are 2 further possibilities. If the increased risk during periods of movement is relatively insubstantial, there is a large range of states where the advantage in food acquisition outweighs the increased risk of migrating, meaning that even relatively small increases in feeding success would be sufficient to make moving beneficial (Fig. 3b). In this case, a species should maintain an interhabitat migratory pattern in most situations. Alternatively, if the risk of predation is substantially heightened during movements between habitats, the trade-off between moving to access food and predation risk will determine whether or not interhabitat migration is beneficial (Fig. 3c). In this case, migratory patterns should change depending on the balance between predation risk and food acquisition.

Where refuge from predation is the main motivation in moving into mangroves, moving outside protective 


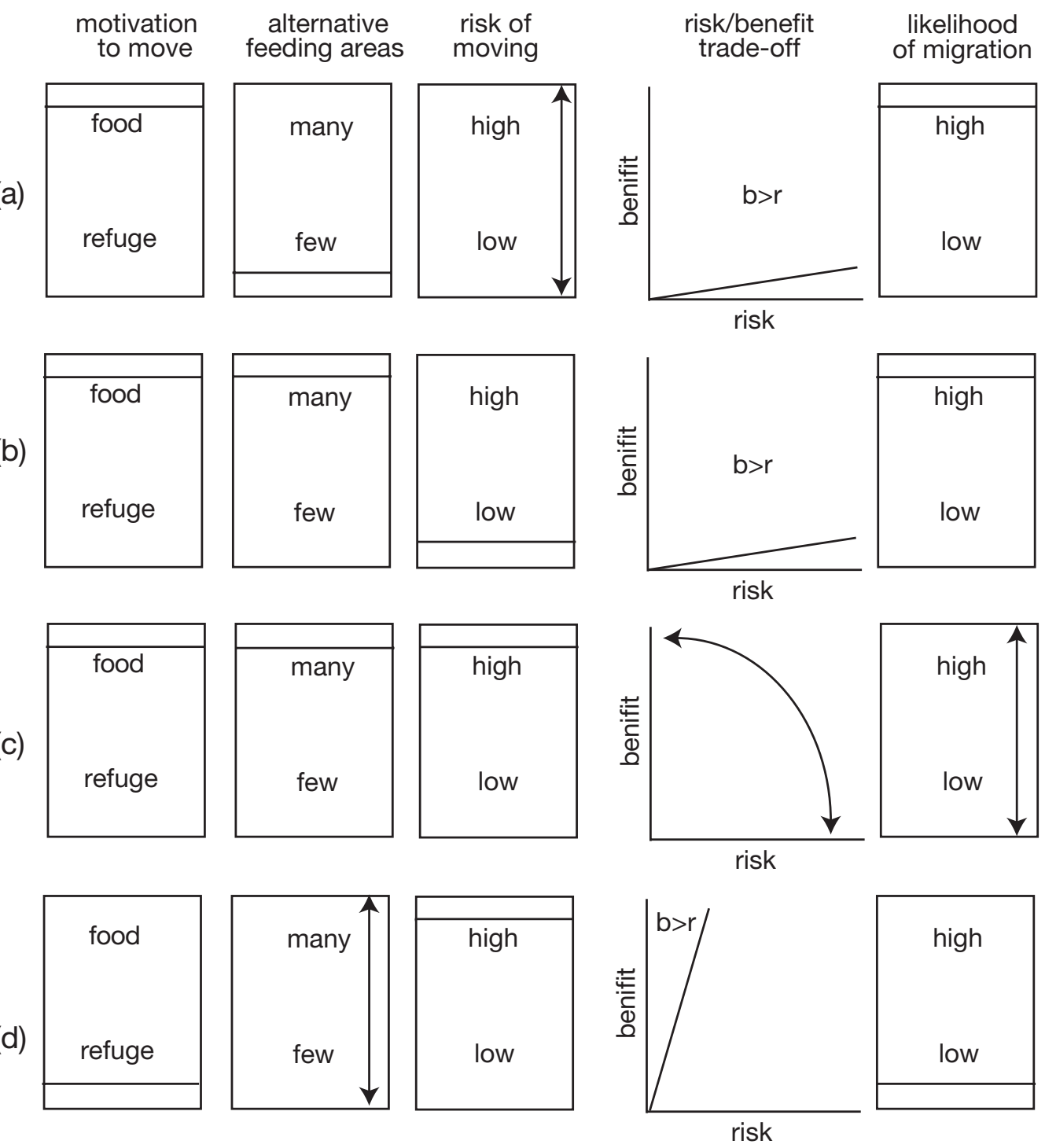

Fig. 3. Four conceptual models of the likelihood of migration into mangroves when they are available. (a) Primary motivation is feeding; there are few alternative feeding areas. (b) Primary motivation is feeding; there are many alternative feeding areas and the risk of moving is low. (c) Primary motivation is feeding; there are many alternative feeding areas and the risk of moving is high. (d) Primary motivation is refuge and consequently the risk of moving is high. Horizontal lines in the box figures indicate the state of motivation to move, alternative feeding areas, risk of moving or likelihood of migration. Double-headed arrows indicate that the same outcome applies across a broad range of levels of availability of alternative feeding areas or risks of moving, or in the case of likelihood of migration, the likelihood depends on the exact trade-off between benefit and risk. The sloped line in the risk-benefit trade-off figures indicates the equivalence of benefit and risk. For states above the line, benefit outweighs risk.

The curved double-headed arrow indicates that the exact nature of the benefit/risk trade-off determines the outcome

habitats should increase risks substantially (otherwise refuge from predation would not be important). In this case, there are many situations where risk of movement may negate the potential refuge value of interhabitat migration (Fig. 3d). Notwithstanding this, migration may still reduce predation pressure if the alternative refuges are less beneficial than mangroves or if their refuge value reduces as the tide rises. Indeed, unless one of these situations prevails there is no reason to move into the mangroves for refuge alone. This suggests that, unless the refuge value of mangroves outweighs that of alternative habitats, leading to lower total mortality, interhabitat migration for predator avoidance only makes sense if there is also a feeding benefit. In many cases where there is little alternative protective habitat for fish that use intertidal structure (Rangeley \& Kramer 1995), it may well be that temporal variation in the refuge value of habitats 
is widespread. For example, if simply occupying shallow water affords refuge by minimising predatory encounters, then movement up the intertidal with the flood tide would allow an animal to remain in shallow water and so maintain that advantage (Ellis \& Gibson 1995). If movement also entailed entering a complex habitat (e.g. mangroves), refuge value effect could be enhanced.

\section{Predator-prey relationships}

Biological connectivity adds to the complexity of predator-prey relationships. Firstly and most obviously, prey need to find alternative refuges when mangroves are unavailable. By necessitating movement between habitats, connectivity provides opportunities for predators to target prey during this vulnerable period. Additionally, intrinsic differences, such as difference in the scale of 'spaces' comprising the structural complexity, mean that the refuge value of different parts of the mangrove IHM will not be equivalent for all species or sizes of fish (Roennbaeck et al. 1999). Secondly, predators need to modify their behaviours and tactics, both to accommodate feeding on temporally available prey (Boyd 1996) and to take advantage of the opportunity afforded by migration between habitats (Tabor et al. 1993). Thirdly, the type and variety of predators in an area will be modified by the constraints imposed by connectivity. Predators need to be able to obtain sufficient prey despite the disruption of prey gaining periodic refuge. This can be achieved by developing special tactics to feed in the refuge or by being able to target times and places where the prey are vulnerable. Consequently, the morphology or behaviour of some predators will effectively exclude them from some areas (Blaber et al. 1985). Notwithstanding the exclusion of some predators, the need to move through a variety of habitats should provide opportunities for a greater variety of predators than if the predator-prey interaction was confined to a single habitat. This diversity is likely because both speciality (tactics or morphology that explicitly suit particular units of the IHM) and flexibility (the ability to feed over multiple units of the IHM) are favoured. Fourthly, connectivity imposes a rhythm to which prey must conform and into which predators can tap to be more successful. For instance, predators may be able to enhance their success by targeting prey forced to move between habitats. The corollary of this is that biological connectivity can determine patterns of feeding activity. Finally, predators and predation pressure will be patchily distributed in space and time. The consequence of this complexity is that there can be no simple 'average' pattern of predation, because the nature of predation and the identity of predators change as different tactics and abilities are advantaged at different points in space-time, meaning that the predator-prey relationship must be viewed in the context of the whole IHM.

Physiological cost

The necessity of movement between habitats imposes physiological costs (Hiddink et al. 2002). Where habitats are in close proximity, these costs may be insignificant. However, where animals need to migrate long distances (e.g. across a shallowly sloping intertidal in an area of large tidal range (Roennbaeck et al. 1999)) or where currents are strong (Trump \& Leggett 1980), the energetic costs may be significant, resulting in poorer condition or slower growth (Trump \& Leggett 1980, Alexander 2002). Consequently, as with patterns of predation risk, the trade-off between benefits (predation refuge, food resources) and physiological costs may be an important modifier of patterns of movement across the intertidal and of the utilisation of mangroves.

\section{CONCLUSION}

For many mobile animals, such as fish, biological connectivity is a necessary consequence of making use of mangroves. It puts limits on the patterns of life possible in mangrove systems, complicates trophic structures, and creates the need for tactics and strategies to meet the challenges imposed by using a habitat mosaic. Biological connectivity means that understandings of trophic relationships, life-history strategies, predation and mortality, and patterns of distribution and abundance must be set in a spatially and temporally variable context. Understanding patterns of ecological forcing is complicated, because controlling mechanisms are likely to interact in space and time and may operate in a habitat other than the one being investigated. This complexity is propagated throughout the mangrove system because the mobility of fish and their flexible foraging tactics gives them a crucial role in coupling habitats and processes (Schindler \& Scheuerell 2002). Additionally, the use of multiple habitats makes fish especially vulnerable to adverse effects of habitat modification, because degradation of any one of the units of a habitat mosaic can affect a species across the whole mosaic (Matheson \& Gilmore 1995).

It is not just the use of multiple habitats that is important. The need to move between habitats means that a series of critical transition zones link the components of 
the habitat mosaic (Levin et al. 2001). These are potential foci for processes governing many aspects of the ecology of mangrove systems because events in these transition zones can drive and regulate patterns of predation and mortality, predator and prey behaviour, the development of predation-avoidance tactics, and feeding and activity patterns. These transition zones are potentially 'hot spots' in space and time: critical bottlenecks controlling the ecological patterns observed across a whole range of habitats associated with mangrove systems, which may be crucial in determining many aspects of the life-histories of species that spend some part of their life-cycles in mangrove systems. Consequently, it may be impossible to understand many patterns and processes by studying them in isolation, and not considering the regulating effect of these bottle necks.

Developing an understanding of the regulating effects of predation at transition zone bottlenecks will be difficult. The complications imposed by connectivity in space and time ensure that many mechanisms will be hard to unravel. Detailed dietary studies can help in determining where in space and time predators feed (e.g. Lutjanus argentimaculatus, Sheaves \& Molony 2000) and the extent to which potential prey species use mangrove forests as feeding grounds. Studies of the patterns and timing of movement of prey species through transition zones can indicate if they are moving rapidly through dangerous zones or are moving slowly as they follow the edge of the tide to feed on newly available resources. Investigating the abundance of mangrove utilising species in areas with and without substantial areas of subtidal refuge habitats will provide information on the relative importance of the availability of alternative habitats in determining mangrove usage. In contrast, determining site-specific impacts of predation and sites-specific mortality rates will be much more challenging, although this is exactly the knowledge needed to build a detailed understanding of the role of transitions zones in the interlinked habitat mosaic.

Despite the obvious consequences and importance of biological connectivity, it has often not been given appropriate consideration in the development of theories and paradigms of mangrove ecology. Too often has it been claimed that mangroves provide refuges from predation or rich feeding areas without considering the implications of refuges or feeding areas being unavailable for a considerable part of the time, or the implications of the need to move between habitat units. Until the fact of biological connectivity is explicitly included in studies of mangrove ecology, a full understanding of the mechanisms underpinning the complex patterns of life in these rich and diverse ecosystems cannot be achieved. We need to consider the nature of the man- grove IHM, factors modifying and controlling connectivity, and the consequences and implications of biological connectivity.

Acknowledgements. I thank A. Dartnell, J. Collins and all the members of the James Cook University Coastal and Estuary Ecosystem Ecology group for their constructive criticism, which greatly improved the manuscript. I also thank the Australian National Tidal Centre for access to their tidal data.

\section{LITERATURE CITED}

Adams SR, Keevin TM, Killgore KJ, Hoover JJ (1999) Stranding potential of young fishes subjected to simulated vessel-induced drawdown. Trans Am Fish Soc 128:1230-1234

Alexander RM (2002) The merits and implications of travel by swimming, flight and running for animals of different sizes. Integr Comp Biol 42:1060-1064

Allouche S (2002) Nature and functions of cover for riverine fish. Bull Fr Peche Piscic 365-366, p 297-324

Alongi DM, Christoffersen P, Tirendi F (1993) The influence of forest type on microbial-nutrient relationships in tropical mangrove sediments. J Exp Mar Biol Ecol 171:201-223

Amarasinghe MD (1997) Ecological functions of mangrove and related ecosystems and their contribution to economic sustainability. Sri Lanka J Aquat Sci 2:1-20

Beck MW, Heck KL Jr, Able KW, Childers DL, Eggleston DB and 8 others (2001) The identification, conservation, and management of estuarine and marine nurseries for fish and invertebrates. Bioscience 51:633-641

Bell JD, Pollard DA, Burchmore JJ, Pease BC, Middleton MJ (1984) Structure of a fish community in a temperature tidal mangrove creek in Botany Bay, New South Wales. Aust J Mar Freshw Res 35:33-46

Bell SS, Brooks RA, Ellis WE (2003) Structural spacing and the determination of habitat complexity: examining the Bartholomew et al. (2000) index. Mar Ecol Prog Ser 248:293-295

Bernatchez L, Dodson JJ (1987) Relationship between bioenergetics and behavior in anadromous fish migrations. Can J Fish Aquat Sci 44:399-407

Blaber SJM (1986) Feeding selectivity of a guild of piscivorous fish in mangrove areas of North-west Australia. Aust J Mar Freshw Res 37:329-336

Blaber SJM, Young JW, Dunning MC (1985) Community sturcture and zoogeographic affinities of the coastal fishes of the Dampier region of north-west Australia. Aust J Mar Freshw Res 36:347-366

Boyd IL (1996) Temporal scales of foraging in a marine predator. Ecology 77:426-434

Chaves P, Bouchereau JL (2000) Use of mangrove habitat for reproductive activity by the fish assemblage in the Guaratuba Bay, Brazil. Oceanol Acta 23:273-280

Crowder LB, Squires DD, Rice JA (1997) Nonadditive effects of terrestrial and aquatic predators on juvenile estuarine fish. Ecology 78:1796-1804

Crowl TA (1989) Effects of crayfish size, orientation, and movement on the reactive distance of largemouth bass foraging in clear and turbid water. Hydrobiologia 183: $133-140$

Davis WP, Taylor DS, Turner BJ (1995) Does the autecology of the mangrove rivulus fish (Rivulus marmoratus) reflect a paradigm for mangrove ecosystem sensitivity? Bull Mar Sci 57:208-214

Duke NC (1992) Mangrove floristics and biogeography. In: 
Robertson AI, Alongi DM (eds) Tropical mangrove ecosystems. American Geophysical Union, Washington, DC, p 63-100

Duke NC, Ball MC, Ellison JC (1998) Factors influencing biodiversity and distributional gradients in mangroves. Global Ecol Biogeogr Lett 7:27-47

Duncan RS, Szelistowski WA (1998) Influence of puffer predation on vertical distribution of mangrove littorinids in the Gulf of Nicoya, Costa Rica. Oecologia 117:433-442

Ellis T, Gibson RN (1995) Size-selective predation of 0-group flatfishes in a Scottish coastal nursery ground. Mar Ecol Prog Ser 127:27-37

Flynn AJ, Ritz DA (1999) Effect of habitat complexity and predatory style on the capture success of fish feeding on aggregated prey. J Mar Biol Assoc UK 79:487-494

Gibson RN (1992) Tidally-synchronised behaviour in marine fishes. In: Ali MA (ed) Rhythms in fishes. Plenum Press, New York, p 63-81

Gibson RN (1999) Movement and homing in intertidal fishes. In: Horn MK, Martin KLM, Chotkowski MA (eds) Intertidal fishes. Academic Press, London, p 97-125

Gibson R (2003) Go with the flow: tidal migration in marine animals. Hydrobiologia 503:1-3

Gundermann N, Popper DM, Lichatowich T (1983) Biology and life cycle of Siganus vermiculatus (Siganidae, Pisces). Pac Sci 37:165-173

Hannan J (1998) Fish recruitment in estuaries. Fish NSW Spring 1998:36

Heath AG, Turner BJ, Davis WP (1993) Temperature preferences and tolerances of three fish species inhabiting hyperthermal ponds on mangrove islands. Hydrobiologia 259:47-55

Heck KL, Jr, Thoman TA (1981) Experiments on predatorprey interactions in vegetated aquatic habitats. J Exp Mar Biol Ecol 53:125-134

Hiddink JG, Kock RP, Wolff WJ (2002) Active pelagic migrations of the bivalve Macoma balthica are dangerous. Mar Biol 140:1149-1156

Hixon MA (1993) Predaton, prey refuges, and the structure of coral reef fish assemblages. Ecol Monogr 63:77-101

Huehner MK, Schramm ME, Hens MD (1985) Notes on the behavior and ecology of the killifish Rivulus marmoratus Poey 1880 (Cyprinodontidae). Fl Sci 48:1-6

Ikejima K, Tongnunui P, Medej T, Taniuchi T (2003) Juvenile and small fishes in a mangrove estuary in Trang Province, Thailand: seasonal and habitat differences. Estuar Coast Shelf Sci 56:3-4

Kneib RT (1997) The role of tidal marshes in the ecology of estuarine nekton. Oceanogr Mar Biol Annu Rev 35: $163-220$

Kok WK, Lim CB, Lam TJ, Ip YK (1998) The mudskipper Periophthalmodon schlosseri respires more efficiently on land than in water and vice versa for Boleophthalmus boddaerti. J Exp Zool 280:86-90

Kruse I, Buhs F (2000) Preying at the edge of the sea: the nemertine Tetrastemma melanocephalum and its amphipod prey on high intertidal sandflats. Hydrobiologia 426: $1-3$

Laegdsgaard P, Johnson C (1995) Mangrove habitats as nurseries: unique assemblages of juvenile fish in subtropical mangroves in eastern Australia. Mar Ecol Prog Ser 126: $67-81$

Laegdsgaard P, Johnson C (2001) Why do juvenile fish utilise mangrove habitats? J Exp Mar Biol Ecol 257:229-253

Laffaille P, Feunteun E, Lefeuvre J (2000) Composition of fish communities in a European macrotidal salt marsh (the Mont Saint-Michel Bay, France). Estuar Coast Shelf Sci 51:
$429-438$

Lehnert RL, Allen DM (2002) Nekton use of subtidal oyster shell habitat in a southeastern US estuary. Estuaries 25: 1015-1024

Levin LA, Boesch DF, Covich A, Dahm C, Erseus C and 7 others (2001) The function of marine critical transition zones and the importance of sediment biodiversity. Ecosystems 4:430-451

Ley JA, McIvor CC, Montague CL (1999) Fishes in mangrove prop-root habitats of Northeastern Florida bay: distinct assemblages across an estuarine gradient. Estuar Coast Shelf Sci 48:701-723

Lowry M (2003) Age and growth of Cheilodactylus fuscus, a temperate rocky reef fish. NZ J Mar Freshw Res 37: 159-170

Matheson RE, Jr, Gilmore RG, Jr (1995) Mojarras (Pisces: Gerreidae) of the Indian River Lagoon. Bull Mar Sci 57: 281-285

McIvor CC, Odum WE (1988) Food, predation risk, and microhabitat selection in a marsh fish assemblage. Ecology 69: 1341-1351

Miranda L, Collazo JA (1997) Food habits of 4 species of wading birds (Ardeidae) in a tropical mangrove swamp. Colon Waterbirds 20:413-418

Moore KA, Anderson BA, Wilcox DJ, Orth RJ, Naylor M (2003) Changes in seagrass distribution as evidence of historical water quality conditions. Gulf Mexico Sci 21: 142-143

Nagelkerken I, van de Velde G (2002) Do non-estuarine mangroves harbour higher densities of juvenile fish than adjacent shallow-water and coral reef habitats in Curacao (Netherlands Antilles)? Mar Ecol Prog Ser 245:191-204

Nagelkerken I, van de Velde G (2004) Are Caribbean mangroves important feeding grounds for juvenile reef fish from adjacent seagrass beds? Mar Ecol Prog Ser 274: 143-151

Nagelkerken I, Kleijnen S, Klop T, Van den Brand R, De la Moriniere EC, Van der Velde G (2001) Dependence of Caribbean reef fishes on mangroves and seagrass beds as nursery habitats: a comparison of fish faunas between bays with and without mangroves/seagrass beds. Mar Ecol Prog Ser 214:225-235

Odendaal FJ, Eekhout S, Brown AC, Branch GM (1999) Aggregations of the sandy-beach isopod, Tylos granulatus: adaptation or incidental-effect? S Afr J Zool 34: 180-189

Paterson AW, Whitfield AK (2000) Do shallow-water habitats function as refugia for juvenile fishes? Estuar Coast Shelf Sci 51:359-364

Polis GA, Strong DR (1996) Food web complexity and community dynamics. Am Nat 147:813-846

Polis GA, Anderson WB, Holt RD (1997) Toward an integration of landscape and food web ecology: the dynamics of spatially subsidized food webs. Annu Rev Ecol Syst 28 1997:289-316

Primavera JH (1997) Fish predation on mangrove-associated penaeids. The role of structures and substrate. J Exp Mar Biol Ecol 215:205-216

Quinn R (1993) What is the importance of wetland and estuarine habitats? Qld Fisherman 11:27-30

Rangeley RW, Kramer DL (1995) Tidal effects on habitat selection and aggregation by juvenile pollock Pollachius virens in the rocky intertidal zone. Mar Ecol Prog Ser 126: 19-29

Robertson AI (1991) Plant-animal interactions and the structure and function of mangrove forest ecosystems. Aust J Ecol 16:433-443 
Robertson AI, Duke NC (1990) Mangrove fish-communities in tropical Queensland, Australia: spatial and temporal patterns in densities, biomass and community structure. Mar Biol 104:369-379

Roennbaeck P, Troell M, Kautsky N, Primavera JH (1999) Distribution pattern of shrimps and fish among avicennia and rhizophora microhabitats in the Pagbilao Mangroves, Philippines. Estuar Coast Shelf Sci 48:223-234

Rosenfeld JS, Boss S (2001) Fitness consequences of habitat use for juvenile cutthroat trout: energetic costs and benefits in pools and riffles. Can J Fish Aquat Sci 58:585-593

Rountree RA, Able KW (1997) Nocturnal fish use of New Jersey marsh creek and adjacent bay shoal habitats. Estuar Coast Shelf Sci 44:703-711

Savino JF, Stein RA (1982) Predator-prey interaction between largemouth bass and bluegills as influenced by simulated, submersed vegetation. Trans Am Fish Soc 111:255-266

Schindler DE, Scheuerell MD (2002) Habitat coupling in lake ecosystems. Oikos 98:177-189

Sheaves MJ (1996) Habitat-specific distributions of some fishes in a tropical estuary. Mar Freshw Res 47:827-830

Sheaves M (2001) Are there really few piscivorous fishes in shallow estuarine habitats? Mar Ecol Prog Ser 222: 279-290

Sheaves M, Molony B (2000) Short-circuit in the mangrove food chain. Mar Ecol Prog Ser 199:97-109

Sheridan P (1997) Benthos of adjacent mangrove, seagrass and non-vegetated habitats in Rookery Bay, Florida, USA. Estuar Coast Shelf Sci 44:455-469

Sogard SM (1992) Variability in growth rates of juvenile fishes in different estuarine habitats. Mar Ecol Prog Ser 85: $35-53$

Editorial responsibility: Otto Kinne (Editor-in-Chief), Oldendorf/Luhe, Germany
Sogard SM, Able KW (1994) Diel variation in immigration of fishes and decapod crustaceans to artificial seagrass habitat. Estuaries 17:622-630

Speirs D, Lawrie S, Raffaelli D, Gurney W, Emes C (2002) Why do shallow-water predators migrate? Strategic models and empirical evidence from an estuarine mysid. J Exp Mar Biol Ecol 280:1-2

Tabor RA, Shively RS, Poe TP (1993) Predation on juvenile salmonids by smallmouth bass and northern squawfish in the Columbia River near Richland, Washington. N Am J Fish Manage 13:831-838

Tahir M (1988) Present status and future scope of fisheries in the Andaman group of islands. J Indian Fish Assoc 18:189-195

Thayer GW, Colby DR, Hettler WF Jr (1987) Utilization of the red mangrove prop root habitat by fishes in South Florida. Mar Ecol Prog Ser 35:25-38

Trump CL, Leggett WC (1980) Optimum swimming speeds in fish: the problem of currents. Can J Fish Aquat Sci 37: 1086-1092

Warren JH (1990) Role of burrows as refuges from subtidal predators of temperate mangrove crabs. Mar Ecol Prog Ser 67:295-299

Wilson JP, Sheaves M (2001) Short-term temporal variations in taxonomic composition and trophic structure of a tropical estuarine fish assemblage. Mar Biol 139:787-796

Woodroffe C (1992) Mangrove sediments and geomorphology. In: Robertson AI, Alongi DM (eds) Tropical mangrove ecosystems. American Geophysical Union, Washington, DC, p 7-41

Yanez-Arancibia A, Lara Dominguez AL, Pauly D (1994) Coastal lagoons as fish habitats. Elsevier Science Publishers, Amsterdam

Submitted: May 24, 2004; Accepted: April 21, 2005

Proofs received from author(s): October 7, 2005 